(c) 2017 IEEE. Personal use of this material is permitted. Permission from IEEE must be obtained for all other uses, in any current or future media, including reprinting/republishing this material for advertising or promotional purposes, creating new collective works, for resale or redistribution to servers or lists, or reuse of any copyrighted component of this work in other works. 


\title{
A System Analysis and Modeling of a HEV based on Ultracapacitor Battery
}

\author{
Mohamed Awadallah ${ }^{1}$, Peter Tawadros ${ }^{2}$, Paul Walker ${ }^{3}$, Nong Zhang ${ }^{4}$, James Tawadros ${ }^{5}$ \\ ${ }^{1}$ School of Electrical, Mechanical and Mechatronic Systems, University of Technology Sydney - UTS \\ Mohamed.M.Awadallah@student.uts.edu.au¹, eng.m.zakaria@gmail.com¹,Peter.Tawadros@uts.edu.au², \\ Paul.Walker@uts.edu.au ${ }^{3}$, Nong.Zhang@uts.edu.au ${ }^{4}$, James.Tawadros@uts.edu.au ${ }^{5}$
}

\begin{abstract}
There is a clear shift toward the implementation of electrified vehicles in the market, influenced by the introduction of stricter mandatory regulations on fuel economy improvement and emissions reduction. Of these vehicles, the penetration of hybrid vehicles in the market has much potential for growth in the next few years. The adoption of these vehicles has been limited by the high cost of HEV's, which have less uptake in developing regions. Considering this point, developing countries would see the greatest benefit in adopting HEV technology. A mild hybrid system has an observable advantage in these markets due to its maximum benefit/cost ratio when compared to a full hybrid, plug-in hybrid or electric vehicles.
\end{abstract}

This paper discusses the development of a mild hybrid system for such markets with a focus on improving drive performance and efficiency. To achieve this, high power density ultracapacitors are used based on their fast charging and discharging characteristics, together with intelligent drivetrain control taking advantage of the ultracapacitors' characteristics to deliver smooth torque delivery during gear change (torquefilling). A comparison and analysis is undertaken, of both conventional powertrain and an otherwise identical powertrain but for the incorporation of components required for the mild hybrid system. Software models simulated the powertrains in specific driving conditions, with observations made of the advantages of MHEV over conventional drivetrains. The model demonstrated increased fuel efficiency and performance.

Keywords - Manual transmission; Mild HEV; Ultracapacitor; Shift quality; Simulation; Torque hole; Vehicle;

\section{INTRODUCTION}

Mild hybrid vehicles represent a compromise between the high cost of fully hybridized vehicles and the high emissions and fuel consumption of conventional internal combustion engine (ICE) powered vehicles. This fundamental observation suggests that mild hybrid vehicles may be well-suited to developing regions. These regions are often price-sensitive but also are most often in need of low-emissions technology. The greater goal of the work described herein is to investigate this identified market need and propose a vehicle that could fulfil the dual goals of having a remarkably low manufacturing cost, but also delivering reasonable emissions performance. This paper specifically investigates the role of ultracapacitors in this vehicle.

Certain technologies form the basis of current automotive transmission technology. Some of these include MT \& AT, with DCT, AMT and CVT forming the semi-automatic transmission type. The manual transmission provides the most economical system for manufacture with an increased power transfer efficiency. However, this is countered by many disadvantages. From a user point of view, there is a reduced customer uptake and a poorer quality in shifting. From an operational sense, there is lessened damping of torque oscillations or step-changes through the driveline when assessed alongside alternate transmission architectures. In addition to this, there is an inability to transmit torque when changing gears. However, in the context of a mild hybrid vehicle, many of these disadvantages may be remedied.

An increase in mortality rates due to air pollution-related disease has been observed in developing regions. These areas generally do not have a high intake of both AT and hybrid/low-emission/zero-emission vehicles, with a lower intake of the latter. These can be attributed to the higher cost associated with their introduction $[1,2]$. Owing to the low-cost of the MT, there is potential for the implementation of a mild hybrid electric powertrain employed with a manual transmission (MT) to improve driving comfort, shifting quality and driveability with an associated reduction in the cost of manufacture, and consequently a reduced cost for customers. Our aim of reducing the impact of air pollution on mortality is realised by developing a practical proof-ofconcept hybrid vehicle suitable for developing regions. This includes a focus on developing a gear-shift control strategy for such a vehicle $[3,4]$.

The utilisation of simulation and rapid prototyping in developing a mild HEV system is discussed. Rapid prototyping methodology has been previously examined in both testing and validating vehicle drive trains with defined drive cycles [5-7]. In the simulation, an 8 degree-of-freedom (DOF) vehicle dynamics model was created using Matlab/Simulink/ Stateflow and sits at the core of the vehicle simulation. The introduction of the dynamics model and control unit is described in previous papers [8-10].

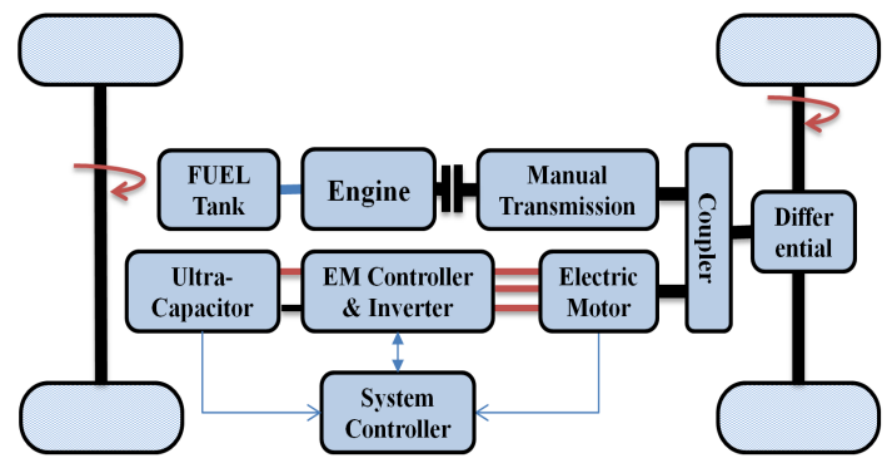

Fig. 1. General Powertrain layout with hybridisation. 
One of the goals of this research is to simplify the architecture to allow for rapid prototyping and validation functions, with a greater view of delivering a low-cost electric propulsion system (EPS). These would be introduced in developing countries where HEV vehicle uptake is necessary. A discussion of the complete system architecture is provided for context when developing and discussing the management strategy model. The integration of various software will allow the models to be run on a real-time platform, with a discussion of results and conclusion to follow. Fig. 1 presents the layout of a mild hybrid, MT equipped powertrain.

\section{MANAGEMENT STRATEGY}

Depending on the vehicle operating conditions, the electric machine (EM) functions as either an electric motor or a generator. This is monitored by an energy management controller (EMC) in four quadrants of operation. Alongside the ICE, the EMC can drive the vehicle or can be driven by it. Fig. 2 demonstrates a rule-based energy management strategy implemented in the EMC. Both the ICE or kinetic energy of the vehicle (regenerative braking) can turn the EM into a generator capable of powering the vehicle on its own. However, this is dependent on the ultracapacitor charging and power demand. Regenerative braking proves to be a vital part of the system, providing a significant influence on the small energy demands of the system. Commuters driving during peak hours, especially in metropolises, can see an energy wastage due to braking of up to $50 \%$ [11].

There is potential for the system to yield many benefits if the EM is operated under ideal conditions. Giving due attention to areas of regenerative braking, electric assist and ICE-generator, the requirements for power storage and flow can be achieved. The operation can be described in four rulebased modes;

1. Regenerative Braking: EM functioning as a generator during vehicle braking and SOC is below highest point. Maximum and minimum electric brake force acting on the wheels is based on the braking torque of the generator.

2. EM as a generator: The EM functioning as a generator during vehicle acceleration, with low SOC and inefficient engine load point without generator load.

3. Torque-hole Mode: The EM provides a tractive force that is linked to gear change during gear change and when SOC is above low point.

4. Idle Mode: The EM runs in idle condition, not performing as a generator or a motor. This mode avoids loading the engine unnecessarily and is typically seen with a fully charged battery and the vehicle travelling at high speeds.

\section{ULTRACAPACITOR}

The traditional implementation of a battery pack in mild hybrids sees an improved suitability to recover braking energy under low or medium load torque conditions at high speed. When the motor operates within the lower rpm range, the back EMF generated by the motor is not enough to charge the highvoltage battery pack. In saying this, there is observable heat loss due to higher charging conditions from conventional electrochemical battery cells, with most battery manufacturers regulating the charging current to under $3 \mathrm{C}$ for

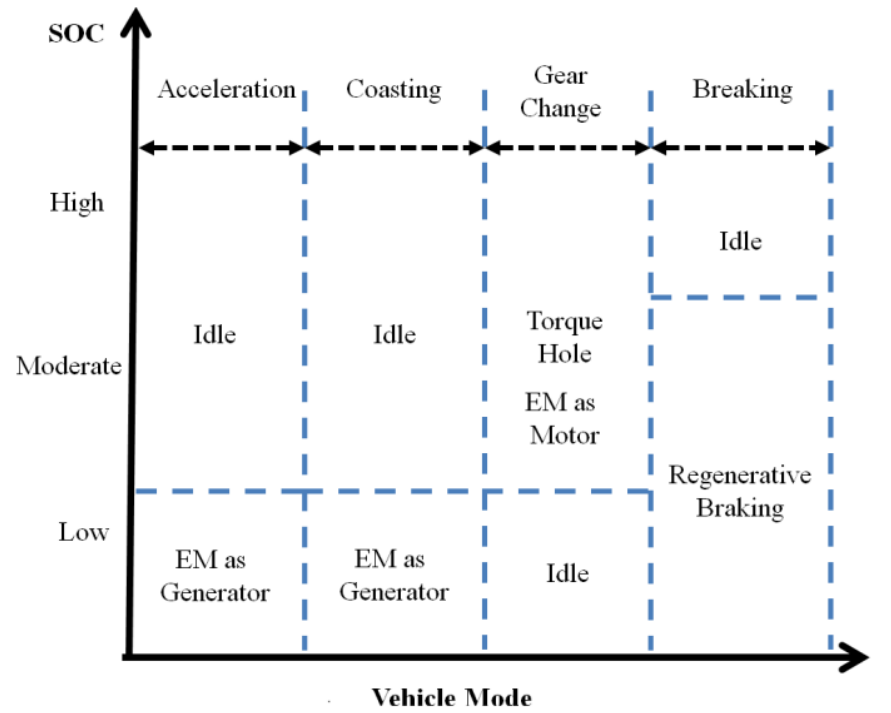

Fig. 2. EM modes of operation

safety. A deterioration in performance and lifecycle is seen when batteries are provided with high power.

The use of ultracapacitors (UC), while retaining many beneficial aspects of electrochemical batteries, appears to be an alternative solution. They can reduce peak battery currents with no chemical variations on the electrodes. This results in a noticeable improvement in the life cycle when compared to batteries. In addition to this comparison, there is an improvement power generation and consumption, based on the ability of the UC to absorb high power demands. The UC's terminal voltage I $\mathrm{s}$ also directly proportional to SOC. Previous papers by the authors have seen both the development and testing of a small-scale drive system [12, $13]$.

State of charge (SOC) is calculated by measuring the energy according to maximum energy with respect to time.

$$
S O C=\frac{E}{E_{\max }}=\frac{V^{2}}{V_{\max }^{2}}
$$

\section{CAPACITY CALCULATION}

The purpose of the mild hybrid is to provide some of the benefits of hybrids at a low incremental cost, which has placed limitations on choosing the UC capacity and size. Assuming the vehicle is operating in charge-sustaining mode allows the UC sizing to be determined. Selecting optimal periods for running the engine at higher load points than road-speed requirements achieves charging. Excess power is used to drive the PM motor.

In previous work, [14], a $1.2 \mathrm{kWh}$ battery module was used in place of the ultracapacitors discussed here. The relatively large size was due to battery chemistry limiting tractive power availability to $80 \%$ of the battery capacity, and $85 \%$ component efficiency of the system for both the motor and controller $[15,16]$. In contrast, a bank consisting of two UC cells of 165 Farad capacity (Maxwell UC BMOD0165 P048 B0110) each rated at 48V (Fig. 3) was used to replace the 96 
$\mathrm{V} / 1.2 \mathrm{kWh}$ NiMH battery module as an energy source. This choice was reached after consideration of the packing constraints, and relevant energy calculations performed to justify the selection.

Total usable electrical energy is where V2 represents the fully charged DC voltage of the UC bank, for two cells, equals to $96 \mathrm{~V}$ and V1, its cut-off voltage, for two cells to be $89 \mathrm{~V}$. The overall bank capacitance is 82 Farad as both cells are connected in series. The overall usable electrical energy seen by using (2)(3) is $53095 \mathrm{~J}$, which is good to provide approximately $5 \mathrm{sec}$ continuous power when the motor is operating at its rated $10 \mathrm{~kW}$ output power. It is worth mentioning that the cut-off voltage is limited by the maximum input current of motor and controller, discussion of these parameters is saved for further research.

$$
\begin{aligned}
& E=P \times T \\
& E=\frac{1}{2} C\left(V_{2}^{2}-V_{1}^{2}\right)
\end{aligned}
$$

\section{Production COST ANALYSIS}

The development of a low-cost electric hybrid drive system for small vehicles was conducted as a proof of concept with an aim to target developing markets which see a correlation with elevated environmental pollutant levels [17, 18]. The development of a hybrid vehicle will have a focus on improving drive (including shift) characteristics with low-cost hardware, for implementation in an automatic vehicle. In recognising the market forces acting as a barrier to entry, a 5\% cost limit on the net manufacturing cost increase of the base vehicle is an assumption made by the authors in representing a realistic cost that would be accepted by end users. With this in mind, this costing has been included as a determinant criterion to cover the total cost of hybridization, including motor, inverter and battery. It is hard to accurately determine the cost of manufacturing in the absence of final designs. McKeever [19] Hadley [20] Wu [21] provide a method for determining the cost of components based on physical performance requirements, resulting in a 2016 figure of $\$ 31.30 / \mathrm{kW}$ calculated for the implementation of this research. This figure sees an addition of approximately $\$ 375.60$ for the motor and controller to the base vehicle.[22, 23].

\section{A. Ultracapacitor cost}

The cost for the UC was approximated at a value of $\$ 450$, resulting in a total additional manufacturing cost of $\$ 825.60$. In comparison, the identical system with a battery module replacing the UC resulted in a net additional manufacturing cost of $\$ 435.60$ [14]. The UC, therefore, represents an almost $90 \%$ cost increase over the battery system, and it is necessary to question whether the benefits justify the cost difference. There is a target to reduce atmospheric particle pollutants in urban regions, and the appropriateness of these vehicles introduced into pre-mature stage markets is taken into account [24]. Whilst both the UC and the battery are effective in reducing emissions output, the UC offers weight benefits, life cycle and power density improvement over the battery, as well as improved energy recapture.

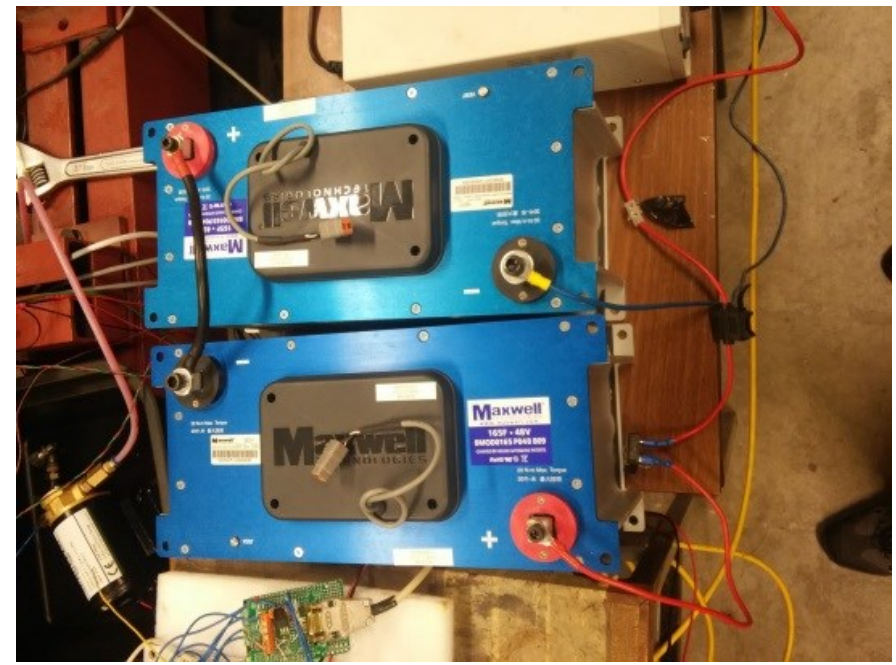

Fig. 3. Supercapacitor bank.

However, in the absence of significant fuel economy and emissions reductions over the battery system, financial considerations are a strong influence. There remains potential for costs to be reduced further. However more research in the area is required to determine how to achieve this.

\section{SySTEM SIMULATION PHASES}

The simulation system will be addressed and discussed. Two main phases make up the vehicle simulation: simulation without time limitations, and real-time simulation. For the latter, the phases of the Real-time simulation are Rapid Prototyping, and HIL [25]. By implementing these simulation phases, there is an observable improvement in development time and prototyping iterations. Overall, this improves the quality of the developed systems [26].

\section{A. Simulation Model}

The vehicle on which the simulation is based is a 1990 Mazda MX-5 (Miata) [27]. As the car uses a low-tech 4cylinder with power output characteristics typical of most Band C-segment vehicles, this vehicle was deemed most suitable. In addition to this, the lightweight and simple body and rear drive powertrain made this vehicle choice appropriate as a basis for research, because of the simplicity of modifying the rear-drive powertrain for hybridization. Table I outlines the vehicle parameters which were used in the model, derived from direct measurements taken from the vehicle as well as factory data. A complete vehicle model in Simulink simulates the manual transmission-based conventional vehicle and runs in different driving cycles are discussed in earlier papers $[8,9]$ The makeup of the model can be seen in Fig. 4, consisting of a driver unit, vehicle control unit, a transmission unit and dynamics unit. The force-generating systems such as tires, powertrain, brakes, suspension, and aerodynamics are taken into account in the model. A PID controller as a driver operating the pedals and shifter according to shift schedule controls the vehicle. Many typical city driving cycles can be simulated in the 'Driver' unit (e.g. NEDC and NYC) to yield more realistic simulation results. 


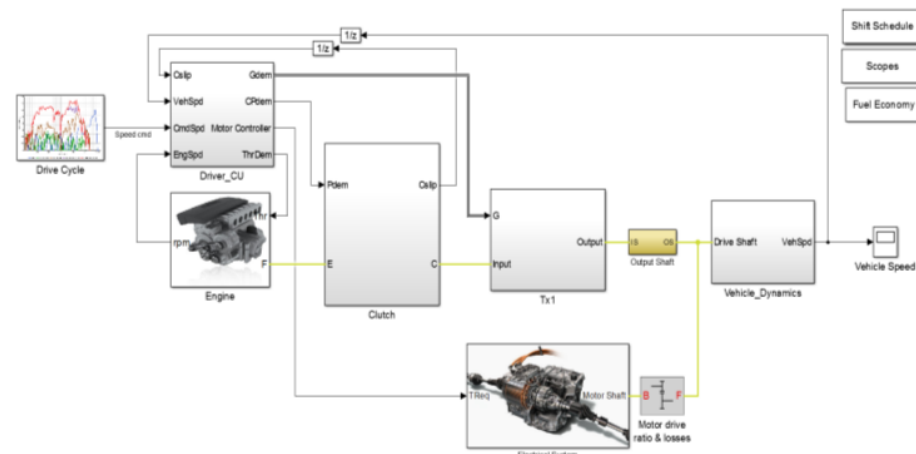

Fig. 4. A high-level view of powertrain structure of the mild HEV model in Matlab/Simulink environment.

Table I. Vehicle Global Specifications.

\begin{tabular}{|c|c|c|}
\hline Component & Parameter & SI Units \\
\hline \multirow{7}{*}{ Vehicle } & Mass as hybrid & $1200 \mathrm{~kg}$ \\
\hline & Frontal area & $3 \mathrm{~m}^{2}$ \\
\hline & Drag coefficient & 0.4 \\
\hline & Distance from CG to front axle & $1.4 \mathrm{~m}$ \\
\hline & Distance from CG to rear axle & $1.6 \mathrm{~m}$ \\
\hline & CG height & $0.5 \mathrm{~m}$ \\
\hline & Tire rolling radius & $0.312 \mathrm{~m}$ \\
\hline \multirow{6}{*}{ Engine } & Type & Spark-Ignition \\
\hline & Maximum power & $70 \mathrm{~kW}$ \\
\hline & Speed at maximum power & $5500 \mathrm{rpm}$ \\
\hline & Maximum speed & $7000 \mathrm{rpm}$ \\
\hline & Idling speed & $800 \mathrm{rpm}$ \\
\hline & Cylinders & 4 \\
\hline \multirow{6}{*}{ Gear ratio } & First & 3.581 \\
\hline & Second & 2.022 \\
\hline & Third & 1.4 \\
\hline & Fourth & 1.03 \\
\hline & Fifth & 0.94 \\
\hline & Final drive ratio & 4.06 \\
\hline \multirow{3}{*}{ Motor } & Voltage & $96 \mathrm{~V}$ \\
\hline & Maximum power output & $10 \mathrm{~kW}$ \\
\hline & Maximum torque & $54 \mathrm{Nm}$ \\
\hline
\end{tabular}

The majority of vehicle simulation software use one of either the forward-looking or the backward-looking modelling approach. By comparing the conventional model with the model adopted by many researchers, an accurate representation of fuel efficiency could be determined for a wide class of vehicles [28]. The adopted model used for the comparison is ADVISOR [29, 30]. A look-up table tabulating fuel rate versus engine operating point (defined by engine speed and torque) is used to assess fuel consumption. A fuel use map provided in ADVISOR was modified for use for this function. The development of an ADVISOR model shared a similar method, where components comparable to this paper's conventional model specifications were chosen and altered to suit the available power, fuel economy and emissions at the exhaust pipe specifications. The simulation used different drive cycles, which included the New European Drive Cycle (NEDC), and New York Drive Cycle (NYC) [31]. The values outlined in Table II support the claim that the simulation model can be accurately analysed in this paper. These are shown in Fig. 5 and Fig. 6. The Energy Management Controller block diagram developed in Simulink is representative of the developmental work on ultracapacitor control. This can be seen in Fig. 7, The SOC variations under the NEDC drive cycle are presented in Fig. 8 with the regenerative braking effective. The simulations are conducted with an initial $\mathrm{SOC}=0$. In both simulations, the results show the proposed control strategy is capable of maintaining the balance of SOC.

Table II. Fuel Economics for vehicle in different drive cycles.

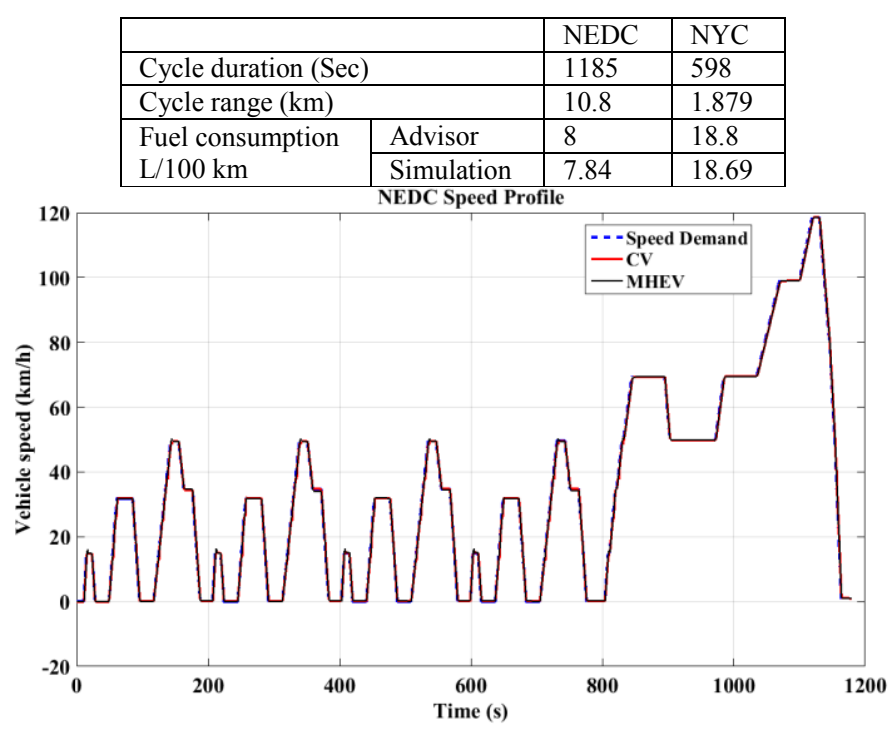

Fig. 5. The speed profile of the NEDC drive cycle.

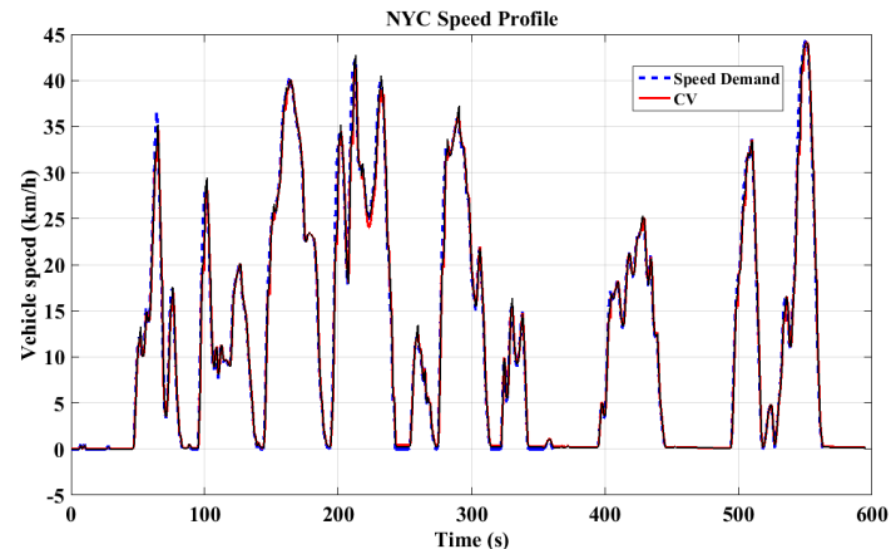

Fig. 6. The speed profile of the NYC drive cycle.

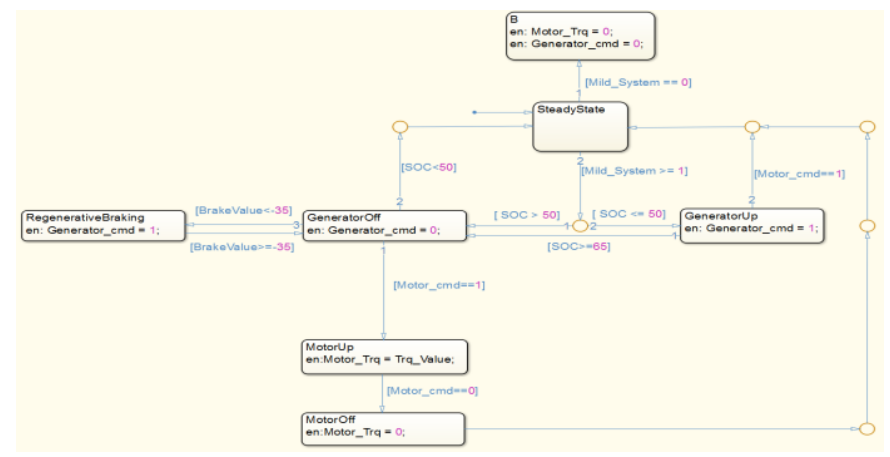

Fig. 7. Energy Management Controller (EMC). 


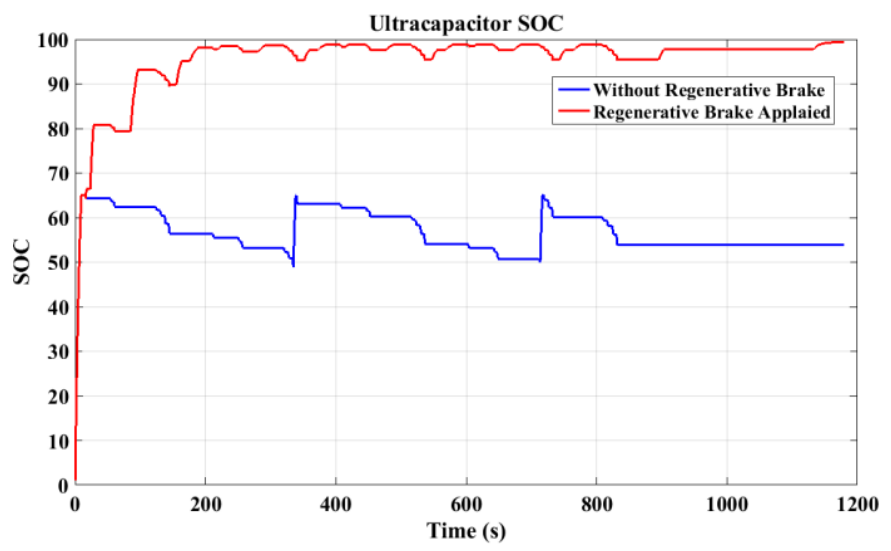

Fig. 8. SOC of ultracapacitors with regenerative braking on NEDC Drive Cycle.

\section{B. Hardware-in-The-Loop}

HIL is used to perform system-level test environments by utilising multiple real-time software environments that interact with commercial hardware, with simulation testing to evaluate performance and analyse interactions between the EPS and ultracapacitor. The simulated system parameters can be easily modified in the software, making it more effective [28, 32]. The PM motor (or 'hardware') is integrated into a comprehensive virtual system. A real PM motor is fixed to an accurate real-time driver, with the dynamometer simulating the virtual vehicle model. This simulation creates a foundation for a wide range of HIL-testing functions. It is vital that the simulation capture the bi-directional interactions between its actual and virtual components so that a real system in the simulation can be appropriately tested. The structure of a motor and ultracapacitor in the loop simulator is illustrated in Fig. 9. Real-time simulation is ensured by using a control unit and real-time tools (dSPACE). More specifically, this allows for the rapid prototyping of different vehicle driveline options without the need to install vehicle components. In addition to this, it makes it possible for the driveline model to command motor speed and measure torque through the dynamometer. The mild HEV hardware-in-loop setup provided in this paper is fully integrated, with the ability to emulate the required vehicle, drivetrain, and driver simultaneously in real-time [33, 34].

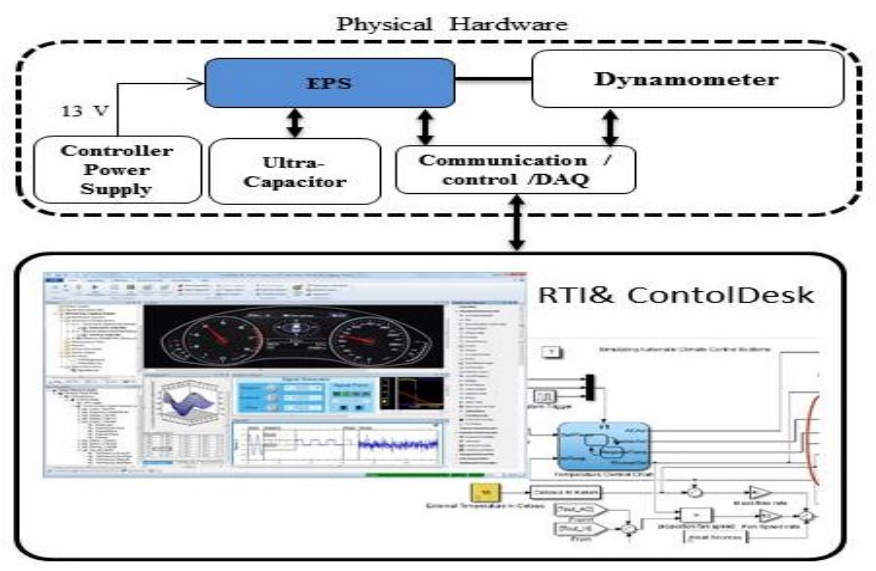

Fig. 9. System level Architecture of UC in HIL.

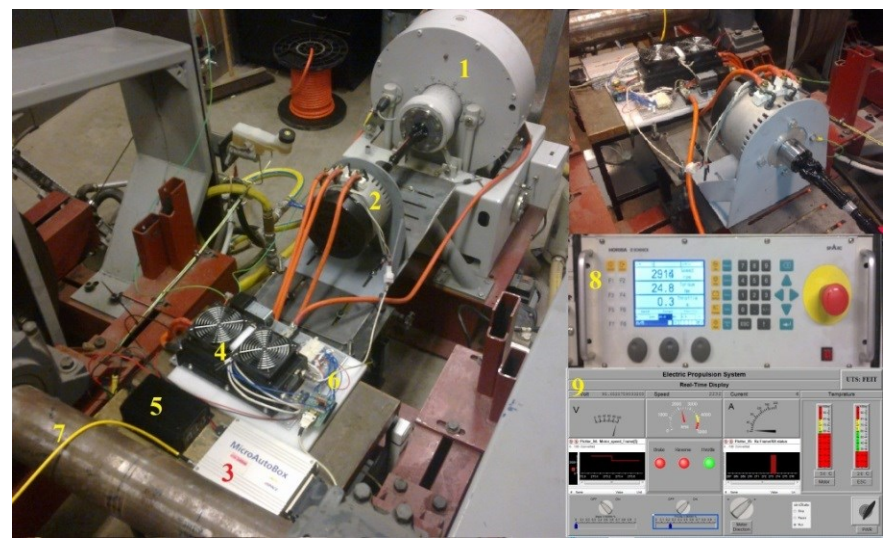

Fig. 10. EPS test facility at UTS. 1-Dynamometer WT190. 2- Mars 0913 PMSM/PM. 3-MicroAutoBoxII. 4-KHB1260124. 5-Step-down 96 V/13.5 V. 6-Relays Board. 7-PC host interface. 8- SPARC control (Dyno stand controller). 9-Control Desk.

The specific implementation of the electric propulsion system (EPS) and interfaces, along with model processing in real-time with electrical hardware functionality and mathematically modelling the motor for simulations is outlined in the Rapid Control Prototyping (RCP) phase. Previous research has determined that phase for both the motor and controller [15, 16]. Fig. 10 displays the facilities used for research and testing, conducted at the University of Technology Sydney.

\section{EXPERIMENTAL SETUP OF HIL}

The motor is controlled using a supervisory controller and an electronic speed controller. The speed control is provided by a Kelly Controls KHB126014, which receives its control signal from a dSPACE MicroAutoBox II, acting as the supervisory controller. The setup is configured this way to allow the MicroAutoBox to act as the virtual driver, which is programmed into ControlDesk and deployed to the dSPACE Realtime Interface (RTI). The combination of the RTI and the MicroAutoBox is required to translate driving commands into motor control and allows the researchers to rapidly build scenarios for testing. A CAN gateway is installed between the motor controller and the MicroAutoBox. This is used to provide feedback signals including motor speed and temperature and is used in the RTI to generate correcting commands to meet the virtual driver input. The motor is mechanically connected to an eddy current brake through a gearbox, simulating vehicle load and reduction. The ICE engine is omitted in this HIL setup. Experimental conditions may be obtained by operating the motor to reach initial test conditions, then switching the required load in using the eddy current brake and initiating the test in the RTI.

The setup for HIL system simulation is best illustrated by considering a drive cycle where the motor is initially idling with a velocity of zero. With an increase in target velocity, the virtual driver integrated into the simulation assesses the difference in actual motor velocities and reacts to increase the speed position as required. MicroAutoBox II receives the speed position signal, processing the signal to the motor through the Electronic Speed Control interface. More torque is produced by the motor as a response to this signal, which is 
measured by assessing the current supplied to the brake or using a shaft-mounted transducer. The values gained from the measured torque are input to the simulation module, which can proficiently assess the impact of the supplied torque on motor velocity. The resulting motor velocity is consequently converted to motor speed. The motor velocity output is transferred to the virtual driver in the RTI, which determines the speed position for the following step by comparison to the driving schedule. The simulation is run simultaneously with the hardware and communicated with MicroAutoBox II throughout the testing duration.

\section{CONCLUSION AND FUTURE WORK}

A low-cost ultracapacitor-based HEV targeted toward developing regions has been proposed. The rule-based control of the system has been determined and programmed into ADVISOR, wherein the implementation of the system was underpinned by a low-tech B/C-segment passenger car based on an early Mazda Miata. This underpinning was selected to allow future prototype development to continue using a commonly-available vehicle that meets $\mathrm{B} / \mathrm{C}$ segment physical characteristics. Benefits of the system were shown to be generally favourable in software, showing minor improvement in fuel economy. The production cost analysis shows the system is affordable within the typical $\mathrm{B} / \mathrm{C}$ segment price range, although there is significant scope to refine the initial work in this area to find further cost-efficiencies. The realtime modelling completed using HIL principles has allowed rapid validation of fundamental system design decisions made for this ultracapacitor-based HEV system, and the initial data generated has validated aspects of the ADVISOR simulation. The HIL simulation could be further refined by replacing the eddy current brake with a DC motor controlled in four quadrants and adding a simulated engine. However the authors consider this development work to be of limited benefit considering the HIL simulation itself needs further validation using the aforementioned future work on a physical prototype. More refinement on the HIL would negate its advantages in development time, and reduce the resources available for the development of the future prototype.

\section{REFERENCES}

[1] R. Baraszu and S. Cikanek, "Torque fill-in for an automated shift manual transmission in a parallel hybrid electric vehicle," in American Control Conference, 2002. Proceedings of the 2002, 2002, pp. 1431-1436.

[2] M. Ehsani, Y. Gao, and A. Emadi, "Fundamentals of Vehicle Propulsion and Brake," in Modern electric, hybrid electric, and fuel cell vehicles: fundamentals, theory, and design, 2 ed: CRC press, 2009.

[3] K.-L. Kuo, "Simulation and Analysis of the Shift Process for an Automatic Transmission," World Academy of Science, Engineering and Technology, vol. 52, pp. 341-347, 2011.

[4] Z. Sun and K. Hebbale, "Challenges and opportunities in automotive transmission control," in American Control Conference, 2005. Proceedings of the 2005, 2005, pp. 3284-3289.
[5] K. Athanasas and I. Dear, "Validation of complex vehicle systems of prototype vehicles," IEEE transactions on vehicular technology, vol. 53, pp. 1835-1846, 2004.

[6] H. Schuette and P. Waeltermann, "Hardware-in-the-loop testing of vehicle dynamics controllers-a technical survey," SAE Technical Paper 0148-7191, 2005.

[7] Z. Filipi, H. Fathy, J. Hagena, A. Knafl, R. Ahlawat, J. Liu, et al., "Engine-in-the-loop testing for evaluating hybrid propulsion concepts and transient emissionsHMMWV case study," SAE Technical Paper 01487191, 2006.

[8] M. Awadallah, P. Tawadros, P. Walker, and N. Zhang, "Eliminating the torque hole: Using a mild hybrid EV architecture to deliver better driveability," in 2016 IEEE Transportation Electrification Conference and Expo, Asia-Pacific (ITEC Asia-Pacific), Busan, South Korea, 2016, pp. 173-179.

[9] M. Awadallah, P. Tawadros, P. Walker, and N. Zhang, "Comparative System Dynamic Modeling of a Conventional and Hybrid Electric Powertrain," in Power Engineering - International conference on Power Transmissions (ICPT 2016), Y. S. Datong Qin, Ed., ed Chongqing, China: CRC Press, 2016, pp. 231-238.

[10] M. Awadallah, P. Tawadros, P. Walker, and N. Zhang, "Dynamic modelling and simulation of a manual transmission based mild hybrid vehicle," Mechanism and Machine Theory, vol. 112, pp. 218239, June 20172017.

[11] J. Ruan, P. Walker, N. Zhang, and G. Xu, "The Safety and Dynamic Performance of Blended Brake System on a Two-Speed DCT Based Battery Electric Vehicle," SAE International Journal of Passenger Cars-Mechanical Systems, vol. 9, pp. 143-153, 2016.

[12] L. Sun and N. Zhang, "Design, implementation and characterization of a novel bi-directional energy conversion system on DC motor drive using supercapacitors," Applied Energy, vol. 153, pp. 101-111, 2015.

[13] L. Sun, M. Awadallah, L. Chi, and N. Zhang, "An Electric Scooter with Super-Capacitor Drive and Regenerative Braking," in SAE 2014 World Congress \& Exhibition, Detroit, Michigan, USA, 2014.

[14] M. Awadallah, P. Tawadros, P. Walker, and N. Zhang, "A Comparative Fuel Analysis of a novel HEV with conventional vehicle," presented at the Vehicular Technology Conference (VTC Spring), 2017 IEEE 85th, Sydney, Australia, 2017.

[15] M. Awadallah, P. Tawadros, and N. Zhang, "Rapid Prototyping and Validation of Mars 0913 Brushless Motor to Develop Mild HEV," in The 7th TM Symposium China (TMC2015), Shanghai, China, 2015, pp. 92-98.

[16] M. Awadallah, P. Tawadros, P. Walker, and N. Zhang, "Selection and Characterisation of PMSM motor for mild HEV Applications," in 29th Electric 
Vehicle Symposium 2016 (EVS29), Montréal, Québec, Canada, 2016, pp. 1276-1286.

[17] K. R. Smith, "Fuel combustion, air pollution exposure, and health: the situation in developing countries," Annual Review of Energy and the Environment, vol. 18, pp. 529-566, 1993.

[18] D. Campbell-Lendrum and C. Corvalán, "Climate change and developing-country cities: implications for environmental health and equity," Journal of Urban Health, vol. 84, pp. 109-117, 2007.

[19] J. W. McKeever, S. Das, L. M. Tolbert, L. D. Marlino, and A. Nedungadi, "Life-Cycle Cost Sensitivity to Battery-Pack Voltage of an HEV," Life, vol. 1, p. 1556, 2000.

[20] S. W. Hadley and T. P. Cleary, "Plug-in Hybrid Electric Vehicle Value Proposition Study-Final Report," 2010.

[21] G. Wu, A. Inderbitzin, and C. Bening, "Total cost of ownership of electric vehicles compared to conventional vehicles: A probabilistic analysis and projection across market segments," Energy Policy, vol. 80, pp. 196-214, 2015.

[22] R. Sharma, M. Bessede, C. Manzie, M. Brear, and R. Crawford, "An economic and in-service emissions analysis of conventional, hybrid and electric vehicles for Australian driving conditions," SAE Int. J. Commer. Veh, vol. 5, pp. 291-298, 2012.

[23] P. Brown, N. Jackson, L. Sykes, J. Wheals, and M. Wiseman, "A Hybrid and Fuel Cell Vehicle Future?," SAE Technical Paper 0148-7191, 2002.

[24] T. Hutchinson, S. Burgess, and G. Herrmann, "Current hybrid-electric powertrain architectures: Applying empirical design data to life cycle assessment and whole-life cost analysis," Applied Energy, vol. 119, pp. 314-329, 2014.

[25] R. Isermann, J. Schaffnit, and S. Sinsel, "Hardwarein-the-loop simulation for the design and testing of engine-control systems," Control Engineering Practice, vol. 7, pp. 643-653, 1999.

[26] Q.-Z. Yan, J. M. Williams, and J. Li, "Chassis control system development using simulation: software in the loop, rapid prototyping, and hardware in the loop," SAE Technical Paper 0148-7191, 2002.

[27] K. Takao and H. Toshihiko, "Vehicle Development through "Kansei" Engineering," SAE Technical Paper 0148-7191, 2003.

[28] S. C. Oh, "Evaluation of motor characteristics for hybrid electric vehicles using the hardware-in-theloop concept," IEEE transactions on vehicular technology, vol. 54, pp. 817-824, 2005.

[29] T. Markel, A. Brooker, T. Hendricks, V. Johnson, K. Kelly, B. Kramer, et al., "ADVISOR: a systems analysis tool for advanced vehicle modeling," Journal of power sources, vol. 110, pp. 255-266, 2002.

[30] A. C. Baisden and A. Emadi, "ADVISOR-based model of a battery and an ultra-capacitor energy source for hybrid electric vehicles," IEEE Transactions on Vehicular Technology, vol. 53, pp. 199-205, 2004.

[31] J. Ruan and P. Walker, "An Optimal Regenerative Braking Energy Recovery System for Two-Speed Dual Clutch Transmission-Based Electric Vehicles," SAE Technical Paper 0148-7191, 2014.

[32] T. Chung, K. Yi, J. Kim, and J. Lee, "Closed-loop evaluation of vehicle stability control (VSC) systems using a combined vehicle and human driving model," SAE Technical Paper 0148-7191, 2004.

[33] J. Allen, "Simulation and Test Systems for Validation of Electric Drive and Battery Management Systems," SAE Technical Paper2012.

[34] H. Fathy, Z. Filipi, J. Hagena, and J. Stein, "Review of hardware-in-the-loop simulation and its prospects in the automotive area," Ann Arbor, vol. 1001, pp. 48109-2125, 2006. 